\title{
Delay in the diagnosis of pulmonary tuberculosis, London, 1998-2000: analysis of surveillance data
}

\author{
Alison Rodger, Shabbar Jaffar, Stuart Paynter, Andrew Hayward, Jacqui Carless, Helen Maguire
}

Noted cases of tuberculosis each year have doubled in London since 1987. In 2000, 12.9 cases per 100000 population in England and Wales were recorded compared with 40.3 cases in London. ${ }^{1}$ A delay in the diagnosis of tuberculosis increases the risk of poor clinical outcome-including death and transmission of tuberculosis. ${ }^{23}$ Understanding which factors influence this delay is crucial for controlling tuberculosis.

Only one small study has previously investigated delays in the diagnosis of pulmonary tuberculosis in the United Kingdom. ${ }^{4}$ Using surveillance data from London, we estimated the delays in diagnosis of tuberculosis and investigated the factors independently associated with delays.

\section{Methods and results}

We analysed surveillance data collected by doctors (1999-2000) and an anonymised national survey (1998) for cases of tuberculosis in London from 1998 to 2000. We calculated the delay in diagnosis as the number of days between the onset of symptoms and diagnosis or the start of treatment (which were on the same day in cases with both recorded). Delay was characterised as greater than the median or at or less than the median. We used unconditional logistic regression to investigate factors that were independently associated with delay.

A total of 1355 patients had a positive result in smear tests of pulmonary sputum; we give results for $853(63 \%)$ about whom data on the time between onset of symptoms and diagnosis had been recorded.
Patients with data and those without were similar for age, sex, and ethnic group.

The median age was 34 (interquartile range 26-51) years; $505 / 849(60 \%)$ of patients were men. A total of 263/842 (31\%) patients were white and 267/842 (32\%) were black; 542/782 (69\%) of patients were born outside the United Kingdom. Median delay was 49 (14-103) days. Univariate analysis showed that factors significantly associated with delay of longer than 49 days until diagnosis or treatment were age, birthplace (United Kingdom or overseas), sex, and ethnic group (table). The geometric mean delay in days were 72 (95\% confidence interval 63 to 80) among white patients and 43 (39 to 45 ) among all other ethnic groups, 72 (66 to 77) among women and 61 (56 to 65 ) among men, and 64 (55 to 74) among those aged $\geqslant 40$ years and 45 (40 to 51) among patients aged $<40$ years. Among patients not born in the United Kingdom, time since entry was significantly positively associated with delay being greater than the median $(\mathrm{P}=0.01)$. In multivariate analysis, delays were more likely for white patients (adjusted odds ratio 1.67 (1.2 to 2.5); $\mathrm{P}=0.01$ ) and women (1.42 (1.1 to 1.9$)$; $\mathrm{P}=0.01)$. Age and birth place were not independently associated with delay.

\section{Comment}

Delay between the onset of symptoms of pulmonary tuberculosis and diagnosis or treatment (median 49 days) was more common for white people and for women. This median delay is similar to findings in other

Odds ratios for delay in the diagnosis of tuberculosis in patients testing positive for tuberculosis in smear tests, London, 1998 to $2000^{*}$

\begin{tabular}{|c|c|c|c|c|c|c|c|c|}
\hline \multirow[b]{2}{*}{ Characteristic } & \multirow[b]{2}{*}{ No $(n=853) \dagger$} & \multirow{2}{*}{$\begin{array}{l}\text { No }(\%) \text { with } \\
\text { longer than } \\
\text { median delay }\end{array}$} & \multicolumn{3}{|c|}{ Unadjusted odds ratio } & \multicolumn{3}{|c|}{ Adjusted odds ratiof } \\
\hline & & & Value & $95 \% \mathrm{Cl}$ & $P$ value & Value & $95 \% \mathrm{Cl}$ & $P$ value \\
\hline \multicolumn{9}{|l|}{ Sex: } \\
\hline Male & 509 & $244(48)$ & 1 & - & \multirow{2}{*}{0.027} & 1 & - & \multirow{2}{*}{0.01} \\
\hline Female & 344 & $196(57)$ & 1.37 & 1.05 to 1.82 & & 1.46 & 1.1 to 1.9 & \\
\hline \multicolumn{9}{|l|}{ Age (years): } \\
\hline$<40$ & 511 & $245(48)$ & 1 & - & \multirow{2}{*}{0.009} & 1 & - & \multirow{2}{*}{0.11} \\
\hline$\geq 40$ & 337 & $192(57)$ & 1.46 & 1.09 to 1.95 & & 1.18 & 0.87 to 1.62 & \\
\hline \multicolumn{9}{|l|}{ Ethnic group: } \\
\hline White & 263 & $163(62)$ & 1 & - & \multirow{4}{*}{0.021} & 1 & - & \multirow{4}{*}{0.03} \\
\hline Black & 267 & $112(42)$ & 0.44 & 0.30 to 0.63 & & 0.52 & 0.33 to 0.80 & \\
\hline Indian subcontinent & 224 & $114(51)$ & 0.61 & 0.42 to 0.89 & & 0.64 & 0.42 to 0.99 & \\
\hline Other & 88 & $43(49)$ & 0.62 & 0.37 to 1.02 & & 0.73 & 0.41 to 1.29 & \\
\hline \multicolumn{9}{|l|}{ Birthplace: } \\
\hline United Kingdom & 240 & $146(61)$ & 1 & - & \multirow{2}{*}{0.0005} & 1 & - & \multirow{2}{*}{0.32} \\
\hline Other & 542 & $255(47)$ & 0.58 & 0.43 to 0.79 & & 0.82 & 0.56 to 1.21 & \\
\hline \multicolumn{9}{|c|}{ Time since entry to United Kingdom§: } \\
\hline$<2$ years & 49 & $16(33)$ & 1 & - & \multirow{3}{*}{0.010} & - & - & \multirow{3}{*}{-} \\
\hline $2-5$ years & 180 & $79(44)$ & 1.73 & 0.87 to 3.43 & & - & - & \\
\hline$>5$ years & 204 & $112(55)$ & 2.65 & 1.34 to 5.25 & & - & - & \\
\hline
\end{tabular}

*Associations between categorical data were assessed using $\chi^{2}$ or Fisher's exact tests, as appropriate. Continuous data were compared using $t$ tests if approximately normally distributed or otherwise using the Wilcoxon test.

†Data are missing for sex in 0, for age in 5, for ethnic group in 11, for birth place in 71, and year of entry to the United Kingdom in 109 cases.

$\ddagger$ Adjusted for sex, age, ethnic group, and whether the patient was born in the United Kingdom.

§Not investigated in the multivariate model.
Infectious Disease

Epidemiology Unit, London School of Hygiene and Tropical Medicine, London

WC1E 7HT

Alison Rodger specialist registrar Shabbar Jaffar senior lecturer

European Centre on the Health of Societies in

Transition, London School of Hygiene and Tropical

Medicine

Stuart Paynter specialist registrar

UCL Centre for Infectious Disease Epidemiology,

Department of

Primary Care and

Population

Sciences, Royal Free

and University

College Medical

School, London

NW3 2PF

Andrew Hayward

senior lecturer

Communicable

Disease

Surveillance Centre

London Regional

Unit, London,

W2 $3 \mathrm{QR}$

Jacqui Carless information officer (TB)

Helen Maguire consultant regional epidemiologist

Correspondence to: A Rodger alison.rodger@

lshtm.ac.uk

BMJ 2003;326:909-10 
large cities in industrialised nations. ${ }^{5}$ This might be because tuberculosis may be suspected and investigated more readily among men or black or Asian people.

Our study was limited by the amount of missing surveillance data. It was also impossible to determine the relative contribution of patient and healthcare provider to the total delay. Potential confounders-for example, coinfection with HIV or the accuracy of the data among patients whose first language was not English-were not taken account of.

Recent campaigns have tried to raise awareness of tuberculosis, particularly among ethnic minority groups. Our data suggest that campaigns also need to be targeted at white people, who comprise a third of cases.

We thank John Watson for access to the anonymised data from the national tuberculosis survey 1998.

Contributors: AR, SJ, SP, and AH conceived and designed the study. AR and SJ conducted the analysis. JC manages the database. AR drafted the paper and all authors revised drafts and approved the final version. AR is guarantor.

Funding: Shabbar Jaffar is supported by a Medical Research Council strategic grant in epidemiology.

Competing interests: None declared.

1 Wright A, Atkinson P, Maguire H. Communicable Disease Surveillance in London 2000. London: Communicable Disease Surveillance Centre,

2 Zahar JR, Azoulay E, Klement E, De Lassence A, Lucet JC, Regnier B, et al. Delayed treatment contributes to mortality in ICU patients with severe active pulmonary tuberculosis and acute respiratory failure. Intensive Care Med 2001;27:513-20.

3 Chin DP, Crane CM, Diul MY, Sun SJ, Agraz R, Taylor S, et al. Spread of Mycobacterium tuberculosis in a community implementing recommended elements of tuberculosis control. JAMA 2000;283:2968-74.

4 Wares D. Delay in diagnosis of tuberculosis: of remaining concern in England and Wales. J Public Health Med 1999;21:355-6.

5 Rodrigo T, Cavla JA, Galdos Tanguis H, Garcia de Olalla P, Brugal MT, Jansa JM. Proposing indicators for evaluation of tuberculosis control programmes in large cities based on the experience of Barcelona. Int J Tuber Lung Dis 2001;5:432-40.

(Accepted 4 December 2002)

\section{Drug points}

Department of Dermatology and Venereology, Government Medical College and Hospital, Sector $32 \mathrm{~B}$, Chandigarh, 160047, India Gurvinder P Tham reader

Mala Bhalla

senior resident

Correspondence:

G P Thami

thamigp@

yahoo.com

BMJ 2003;326:910
Erythromelalgia induced by possible calcium channel blockade by ciclosporin

Gurvinder P Thami, Mala Bhalla

Erythromelalgia, a symptom complex of painful inflammatory vasodilatation of extremities, is usually idiopathic or due to thrombocythaemia. It has often been regarded as inverse Raynaud's phenomenon, rarely induced by calcium channel blockers. ${ }^{1}$ We report a case of erythromelalgia induced by ciclosporin.

A 37 year old man had been taking ciclosporin $75 \mathrm{mg}$ twice daily for psoriasis vulgaris for four weeks when he developed marked erythema, oedema, and tenderness over fingers and toes. Symptoms increased with warmth and were relieved partially with cold compresses. His full blood count, serum biochemistry, urine analysis, and collagen profile were normal. Erythromelalgia induced by ciclosporin was considered, and the drug was withdrawn. Lesions regressed within a week but recurred when ciclosporin was restarted. No recurrence was observed at one year follow up.

Erythromelalgia is a multifactorial peripheral vascular phenomenon akin to sympathectomy, with attenuation of vasomotor tone probably mediated through vasoactive substances and drugs such as nifedipine, nicardipine, verapamil, and bromocriptine.

Ciclosporin, a calcineurin antagonist, acts by inhibiting calcium-calmodulin signalling systems of target cells in a way similar to calcium channel blockers. ${ }^{2}$ It binds to calmodulin, with a consequent inhibition of dephosphorylation of calmodulin induced kinases and other calmodulin dependent intracellular activities. ${ }^{3}$ Ciclosporin also affects the calmodulin regulated activity of the actomyosin complex of smooth muscle of peripheral vessels, which leads to vasodilatation. In this way, ciclosporin has also been observed to potentiate the peripheral vasodialatory effects of calcium channel blockers.

The erythromelalgia in this patient may have been the result of ciclosporin acting in a similar way to calcium channel blockers. Though burning sensation of the hands and feet has been mentioned as an adverse effect in the product leaflet of ciclosporin (Panimun Bioral, Panacea Biotec) and a leg pain syndrome has been described, an erythromelalgia-like effect has not been reported. ${ }^{5}$ This possible vasoactive effect of ciclosporin needs further evaluation given that vasoactive peptides may be present in psoriasis.

Funding: None

Competing interests: None declared.

Levesque H, Moore N, Wolfe CM, Courtois M. Erythromelalgia induced by nicardipine. $B M J$ 1989;298:1252-3.

Kanitakis J, Thivolet J. Cyclosporine. An immunosuppressant affecting epithelial cell proliferation. Arch Dermatol 1990;126:369-75.

Colombani P, Robb A. Hess A. Cyclosporin A binding to calmodulin: a possible site of action on T-lymphocytes. Science 1985;228:337-9.

4 Von Vigier RO, Fossali E, Edefonti A, Vogt B, Bianchetti MG. Cyclosporin Von Vigier RO, Fossali E, Edefonti A, Vogt B, Bianchetti MG. Cyclosporin
enhances the tendency towards oedema and flushing noted on dihydroenhances the tendency towards oedema and flushing noted on dihyd

5 Naredo Sanchez E, Balsa Criado A, Sanz Guajardo A, Pantoja Zarza L, Martin Mola E, Gijn Banos J. Leg bone pain syndrome due to cyclosporine in a renal transplant patient. Clin Exp Rheumatol 1994;12:653-6.

\section{Corrections and clarifications}

Mark Twain on evidence based practice

This Endpiece attributed the quotation "It ain't what people don't know that hurts them it's what they know that ain't so" to Mark Twain (25 January, p 211). However, a reader has corrected us, confirming that this quotation is attributable not to Mark Twain but to Josh Billings (and in support has cited various sources, including the Penguin Dictionary of Modern Humorous Ouotations, Penguin, 1987). A trawl of the web, however, has revealed that people often get it wrong, attributing the quotation in question not to Josh Billings but to Mark Twain-or to Will Rogers or Herbert Stein (or possibly others). The quotation always appears in slightly different forms; indeed, the one cited in the Penguin dictionary is not exactly the same as the one we published.

Filler: He died "peacefully" at home

Although editors are aware of the dangers of confusing words that differ in spelling by only one letter, there is always a danger that the wrong word will slip through. Unfortunately, this is what happened in this account by David Veale of the death of his father-we used the word prostrate, rather than prostate (12 April, p 792). 